\section{Malaria grave por Plasmodium falciparum}

Severe malaria due to plasmodium falciparum

\section{Sr. Director:}

Presentamos el caso de un varón de rasgos asiáticos encontrado en la vía pública con bajo nivel de conciencia. Al ingreso en Urgencias de nuestro hospital estaba en coma (8 puntos en la Escala de Coma de Glasgow) y presentaba hipotensión moderada, taquicardia e ictericia.

En la analítica destacaba hipoglucemia, hipoproteinemia y cifras elevadas de creatinina, transaminasas, bilirrubina y LDH, así como acidosis láctica, pancitopenia, y un TTPA alargado. La punción lumbar y el TAC de cráneo no mostraron datos patológicos. No se detectaron tóxicos en orina y los niveles de paracetamol en sangre no estaban elevados.

El paciente fue ingresado en la Unidad de Cuidados Intensivos y conectado a ventilación mecánica, desarrollando deterioro hemodinámico con necesidad de apoyo inotrópico, disfunción renal, que requirió hemofiltración, y una intensa acidosis láctica. Falleció en shock refractario a las $8 \mathrm{~h}$ de su ingreso.

El frotis sanguíneo evidenció intensa parasitación por Plasmodium falciparum (anillos con 2 nucleosomas, varios parásitos en un mismo hematíe y pigmento de Maurer característico de esta especie). Posteriormente, se conoció que el paciente había estado en Nueva Guinea en la semana previa.

P. falciparum es la especie que causa más complicaciones graves y fallo multiorgánico ${ }^{1,2}$. La Organización Mundial de la Salud considera malaria grave cuando aparece disminución del nivel de conciencia, signos neurológicos, disfunción renal, shock/hipotensión, recuento de parásitos $>5 \%$, hematocrito $<15 \%$, signos de sangrado, coagulación intravascular diseminada, ictericia, edema pulmonar, hipoxia, acidosis o hipoglucemia.

El diagnóstico a través del examen de gota gruesa y extensiones de sangre es la principal prueba diagnóstica. También se puede diagnosticar mediante detección antigénica por inmunocromatografía y por $\mathrm{PCR}^{3,4}$.

El tratamiento de las formas graves, en las que no se puede emplear la vía oral, se realiza con la administración intravenosa de dihidrocloruro de quinina, junto con doxiciclina o clindamicina (de elección en embarazadas y en niños menores de 8 años). También se puede emplear arteméter intramuscular, artesunato intravenoso o intramuscular $y$ artemisina rectal ${ }^{2,3,4}$.

El manejo general de los casos graves incluye: posición elevada de la cabeza, control de la fiebre y convulsiones, aporte adecuado de fluidos y oxígeno y, si es necesario, administración de vitamina $\mathrm{K}$, transfusión de hemoderivados, ventilación mecánica, hemofiltración y/o hemodiálisis. Se debe considerar la exanguineotransfusión cuando la parasitemia es mayor del $10 \%$ y en caso de coma, fallo renal o síndrome de distrés respiratorio agudo. La exanguineotransfusión elimina los hematíes parasitados, toxinas y mediadores. Debe realizarse junto al tratamiento farmacológico hasta que la parasitemia sea menor del $<5 \%{ }^{5}$.

Nuestro país no es zona endémica de paludismo y los casos importados no son frecuentes (377 casos declarados en el año 2006 en toda España). Sin embargo, el incremento en los últimos años de inmigrantes, turistas y cooperantes ha hecho que esta patología deba ser tenida en cuenta, incluso en situaciones de síndrome de respuesta inflamatoria sistémica y fallo multiorgánico de causa desconocida, debiendo realizarse el examen de gota gruesa o frotis sanguíneo lo más precozmente posible, con el objeto de poder instaurar el tratamiento adecuado con antipalúdicos. Pese a que no exista una alta evidencia en la bibliografía, se debe considerar la exanguineotrasnfusión en las formas graves o parasitemias elevadas.

\section{Bibliografía}

1. Krishnan A, Karnad DR. Severe falciparum malaria: an important cause of multiple organ failure in Indian intensive care unit patients. Crit Care Med. 2003;31:2278-84.

2. White NJ. The management of severe falciparum malaria. Am J Respir Crit Care Med. 2003;167:673-4.

3. WHO Guidelines for the treatment of malaria. [consultado 11/5/ 2009]. Disponible en: http://www.who.int/malaria/docs/Treat mentGuidelines2006.pdf.

4. Leder K, Weller PF. Treatment of falciparum malaria. [consultado 24/5/2009].Disponible en: Up To Date Online 17.1.

5. Riddle MS, Jackson JL, Sanders JW, Blazes DL. Exchange transfusion as an adjunct therapy in severe Plasmodium falciparum malaria: a meta-analysis. Clin Infect Dis. 2002;34:1192-8.

J.A. Arboleda Sánchez $z^{\mathrm{a}, *}$, V.M. Aguilar Urbano ${ }^{\mathrm{b}}$, F.J. García Rodríguez ${ }^{\mathrm{a}}$ y M.I. Mata Vázquez

aUnidad de Cuidados Intensivos, Hospital Costa del Sol, Marbella, Málaga, España

'Unidad de Digestivo, Hospital Costa del Sol, Marbella, Málaga, España

'Unidad de Hematología, Hospital Costa del Sol, Marbella, Málaga, España

*Autor para correspondencia. Correos electrónicos: med007460@saludalia.com (J.A. Arboleda Sánchez). 